\title{
Conclusion and Policy Implications to "Climate Smart Agriculture: Building Resilience to Climate Change"
}

\section{David Zilberman}

\begin{abstract}
The efforts to adapt to climate change in developing countries are in their infancy, and hopefully CSA will be a major contributor to these efforts. But CSA itself is evolving, and there is a growing need to refine and adapt it to the changing realities. This section of the book focus on the implications of the empirical findings for devising effective strategies and policies to support resilience and the implications for agriculture and climate change policy at national, regional and international levels. This section is built upon the analysis provided in the case studies as well as short "think" pieces on specific aspects of the policy relevance issues from policy makers as well as leading experts in agricultural development and climate change. The case study provided concrete illustrations of the conceptual and theoretical framework, taking into account the high level of diversity in agro-ecological and socioeconomic situations faced by agricultural planners and policy-makers today. While the case studies demonstrate the diversity of challenges facing farmers around the world, they also indicate unifying characteristics imposed by climate change on agricultural decision making and the potential for the CSA approach to address them.
\end{abstract}

Smallholder farms and rural communities in developing countries are especially vulnerable to the impacts of climate change. Climate change will exacerbate existing challenges of resource scarcity, credit constraints, infrastructure limitations, and incomplete information and markets. There is already evidence of the perception and reality of climate shocks, and a growing need for effective adaptation strategies. Climate Smart Agriculture (CSA) is a framework for developing decision support systems at the farm and policy level. It aims to provide principles to identify technologies, management tools, and policies that will enable farmers to adapt to challenges of climate change while maintaining and improving societal wellbeing.

\footnotetext{
D. Zilberman $(\square)$

Department of Agriculture and Resource Economics, University of California Berkeley,

Berkeley, CA, USA

e-mail: zilber11@berkeley.edu
} 
CSA is based on the recognition of heterogeneity among farmers and regions in terms of socio-economic and agro-ecologic conditions, which emphasizes the need to understand the distribution of impacts arising from severe weather events and shifting climate. In general, heterogeneity and the randomness of impacts increase the value of having access to a wide range of differentiated strategies, rather than to uniform prescriptions. It also recognizes the high degree of uncertainty and the dynamic nature of climate change, and thus emphasizes the importance of continuous learning and strategic adaptation to changing conditions and new information. Because we are at the early stages of climate change, we emphasize the capacity to adapt to increased likelihood of extreme events, while recognizing that climate change may require more transformative changes in technologies and relocation of production practices in response to permanent and significant changes in weather patterns.

This book starts with an overview of major themes including the evolution of CSA, mechanisms of innovation and institutional change that will influence CSA, and the aspects of climate change that may addressed by CSA. The main part of the book consists of case studies from many regions around the world that analyze adaptation decisions, as well as document barriers to adoption of effective adaptation actions. The emphasis is on developing countries, although we also bring examples from the U.S. to demonstrate that even in highly commercialized systems using advanced technologies, gains can be achieved from access to better information and enhanced ability to adapt to changes proactively. While the case studies demonstrate the diversity of challenges facing farmers around the world, they also indicate unifying characteristics imposed by climate change on agricultural decision making and the potential for the CSA approach to address them.

Targeted Solutions to Specific Problems Heterogeneity suggests that we cannot expect universally applicable solutions, but rather encourage a process to develop solutions that are most appropriate for a given location. More frequent weather extremes and uncertainty regarding longer-term changes in weather mean that a range of targeted solutions - both on and off farm -must be developed that enable farmers to flexibly respond to current conditions and adapt to shifts in climate patterns.

Quantitative Evidence-Based Solutions To identify differentiated solutions best fit to specific situations requires quantitative analysis based on empirical data and appropriate analytical tools. In particular, more emphasis must be given to understanding the distribution of impacts, instead of relying on average impacts on a "representative" farm household. CSA aims to capitalize on growing sources of data and analytical tools to utilize them, including integrating ever more sophisticated GIS information into more traditional econometric analyses and simulation modelling. Solutions are derived both by quantifying technological feasibilities, consumer demand, and biophysical and behavioral constraints.

Adaptive Learning Because of ongoing processes of climate change and technological progress, information is accumulated and new opportunities arise. Thus optimal solutions are changing over time and across locations. The case studies indicate several means of enhancing adaptive learning amongst producers as well as policy-makers including improved analytical tools, improving information channels 
between producers, policy-makers and analysts, and building flexibility into agricultural support services such as agricultural knowledge and extension services as well as input and output markets.

Opportunity and Social Costs The analysis in the case studies indicates that climate change already has some impacts on the opportunity costs associated with alternative agricultural development pathways - and is likely to have even more in the future. Approaches to evaluating alternative solutions and new opportunities that explicitly consider changes inopportunity costs imposed by climate change at different locations can be achieved through better utilization of modelling tools and innovative datasets.

Risk and Risk Aversion We have long been aware that the economic well-being of farmers is affected significantly by risky outcomes and their actions are impeded by risk and loss aversion. Climate change augments the importance of building institutional capacity for dealing with risks and uncertainty. CSA emphasizes introduction of institutions that provide enhanced information to reduce risk as well as institutions, such as insurance markets, that will allow farmers to reduce the cost of risk and loss aversion.

Input Use Efficiency and Precision Not all applied inputs are utilized productivity. The residual is frequently a source of pollution - as well as a cost to the producers. Improving input use efficiency under increasing uncertainty climate change imposes is clearly an area where considerable social and private gains can be realized. Technologies that enhance precision of farming enable farmers to adapt input use to variability in climatic conditions could offer significant improvements in terms of both higher net revenues and lower yield variability. Policies that lead to develop and enhance adoption of affordable technologies that increase precision and input use efficiency may enable farmers in developing countries to "leap-frog" past conventional, often wasteful and costly, input application.

No Regrets Policies Given the uncertainty of climate predictions and risk aversion, it is a priority in CSA to identify activities that will address climate change risks but will enhance wellbeing and improve livelihood regardless of changes in climatic conditions.

Flexibility Given changes in climatic, technological and socioeconomic conditions and a high degree of uncertainty, CSA strategies aim to avoid costly irreversible choices in favor of making decisions that allow modification in response to changing conditions.

Resilience Because climate change may expose farms to severe climatic and economic shocks, CSA encourages developing the capacity to withstand, or rebound afterwards, to these shocks. Resilience can be enhanced through better technologies, improved infrastructure, and reliance on institutional mechanisms (e.g. access to financial products).

Innovative Capacity A key for CSA is having innovative capacity that can produce new solutions taking into account new scientific knowledge and understanding of 
climate change. Innovations may be both technological and institutional. Implementation of innovations requires enabling policies, including investment in infrastructure and extension, and reducing transaction costs that will enable establishment of supply chains and organizations to implement innovations.

Market-Based Solutions Effectively governed markets enhance trade opportunities that can increase efficiency in resource allocation, which in turn is important for the diffusion of low cost solutions and reductions in variability of supply. The CSA approach encourages evaluating the role of trade and trade regulations in capturing these benefits, allowing for innovative market solutions to address risks and environmental side effects of environmental activities.

Supply Chains Farmers and other actors in agriculture are linked across space and time by supply chains. Adaptation to climate change occurs throughout supply chains, and effective farm level adaptation is dependent on effective adaptation throughout the supply chain. Thus greater integration of supply chain governance is needed in the design of farm level adaptation strategies.

The analyses throughout the book emphasize the importance of designing effective policies. Climate smart policies will develop mechanisms to monitor climate and other conditions, assess situations, and be able to respond to changing realities. Furthermore, policies need to enhance resilience and capacity to adapt to changing agro-climatic conditions. These policies will be part of an overall policy environment that aims at sustainable development, namely assuring that the current generation will continue experiencing increased food security while the next generation will not be worse off than the current one.

Improving knowledge systems to meet climate challenges will require investment in infrastructure that allows for collection of spatial data on climatic conditions, agricultural performance and economic conditions at various scales. There is a need to invest in analytic capacity to utilize the data to develop better quantitative understanding of weather patterns, and related behavioral and agro-ecological responses. Furthermore, utilizing this knowledge will require, first an investment in outreach capacity will disseminate new knowledge and update information at different levels of decision making, and second, an investment in response capacity. This capacity will combine both short term capabilities that enable early warning and response systems as well as long term capabilities that will enhance resilience, adaptation, and contribute to sustainable development.

Adaptation capacity begins with investments in and incentives for innovation. This implies both access and utilization of new technologies and management practices developed throughout the world. Access to new technologies means establishing policies and institutions to reduce intellectual property rights and regulatory barriers. In particular, regulations need to balance gains from emerging technologies with risk considerations. Further, local research and outreach capacity is needed to fit technologies and management practices to local conditions.

Rapid response to crisis and long-term adaptation are hindered by lack of roads, electricity, water, and storage capacity. While generally investments in these forms of infrastructure are 'no regret' policies, it is important to use sound analysis integrating effects of climate change to take into account net social benefit and cost. 
Namely, the consideration of viability of certain locations in the long-run, and the environmental and social implications of investments.

Development and resilience in many regions is constrained by lack of access to markets (inputs and outputs), as well as financial constraints. Investment in physical infrastructure can reduce some of these constraints by reducing the cost of doing business, but there is a need for improved institutional capacity. There is a need to expand and improve the supply chains of credit and farm-level inputs and outputs. Developing such supply chains requires strong involvement of the private sector, sometimes in partnership with the public sector, within an improved policy environment. For example, private investment in storage and product processing capacity can be augmented and coordinated with public investment in improved physical infrastructure and training. Public-private partnerships can be established to share risk and obtain finance for joint projects.

Climate smart policies will emphasize incentives and capabilities to encourage improved decision-making at the farm-level. This includes the adoption of best feasible technologies, improved input use, and post-harvest practices. Establishment of extension and improved supply chains may go a long way to meet this objective. Governments may also consider introducing insurance schemes with low transaction costs and moral hazard potential to reduce the cost of risk and risk aversion. Further, governments may provide input subsidies in short-term situations in which learningby-doing is needed, as well as insured and subsidized credit. These activities should be designed to induce transition to sustainable and economically viable practices.

Climate change is a dynamic process marked with random shocks that may result in significant short-term losses and may make some regions economically unviable. Furthermore, policy design will combine both efficiency and distributional considerations. Climate smart policies may consist of cash transfers that sustain individuals at a minimum level of income and promote transition to more sustainable livelihood, which may include migration.

These policies may be costly and one of the major challenges is to optimize the use of funds given budget and credit constraints. Developing evaluation procedures to assess outcomes on efficiency and equity measurements will allow for creating targeting criteria. Thus policies will vary across location and over time to reflect differences in expected net benefit. Furthermore, one of the challenges of climate smart policies is to develop financial mechanisms and political initiatives that will expand the range of resources available for investment.

This book aims to present the state of the art of CSA, both conceptually and by bringing together case studies and perspectives that will improve the management of agriculture in the era of climate change. The efforts to adapt to climate change in developing countries are in their infancy, and hopefully CSA will be a major contributor to these efforts. But CSA itself is evolving, and there is a growing need to refine and adapt it to the changing realities. We look forward to further efforts in this area as part of the increasing commitment and effort to address the challenges of climate change and sustainable development. 
Open Access This chapter is distributed under the terms of the Creative Commons AttributionNonCommercial-ShareAlike 3.0 IGO license (https://creativecommons.org/licenses/by-nc-sa/3.0/ igo/), which permits any noncommercial use, duplication, adaptation, distribution, and reproduction in any medium or format, as long as you give appropriate credit to the Food and Agriculture Organization of the United Nations (FAO), provide a link to the Creative Commons license and indicate if changes were made. If you remix, transform, or build upon this book or a part thereof, you must distribute your contributions under the same license as the original. Any dispute related to the use of the works of the FAO that cannot be settled amicably shall be submitted to arbitration pursuant to the UNCITRAL rules. The use of the FAO's name for any purpose other than for attribution, and the use of the FAO's logo, shall be subject to a separate written license agreement between the FAO and the user and is not authorized as part of this CC-IGO license. Note that the link provided above includes additional terms and conditions of the license.

The images or other third party material in this chapter are included in the chapter's Creative Commons license, unless indicated otherwise in a credit line to the material. If material is not included in the chapter's Creative Commons license and your intended use is not permitted by statutory regulation or exceeds the permitted use, you will need to obtain permission directly from the copyright holder.

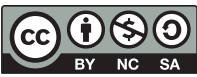

